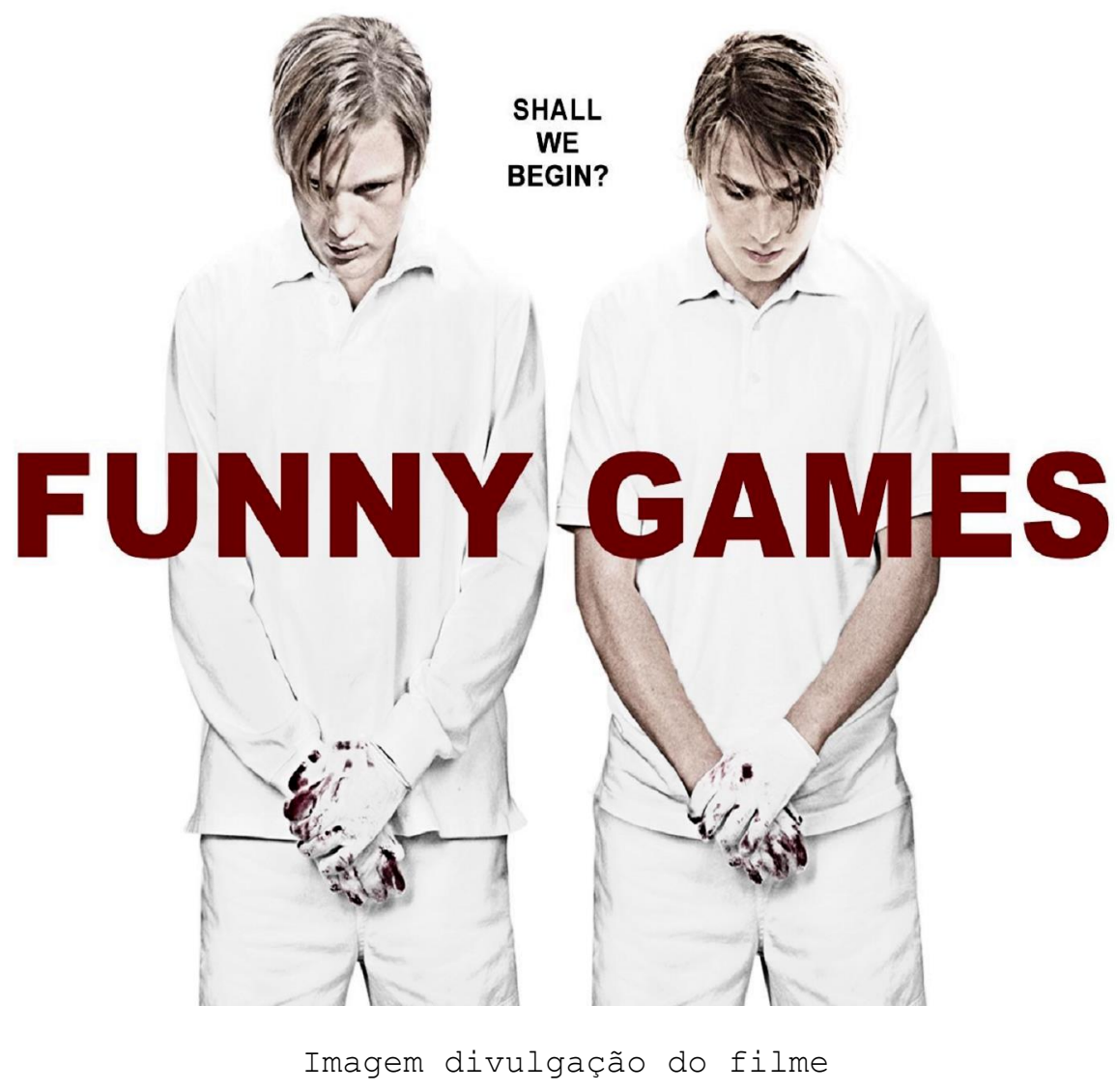

\title{
Violência em três quadros. Como falar sobre?
}

\section{Carla Damêane P. Souza}

Aluna do Programa de Pós-Graduação em Letras Estudos
Literários/UFMG, na linha de pesquisa Literatura e Outros
Sistemas Semióticos.

\section{Resumo}

As relações entre comunicação e representações iconográficas nos dias atuais superam o esperado desde o descobrimento da fotografia e do cinema. Existem artistas que utilizam a arte para colaborar com a política da exploração de assuntos que estão na moda, outros tratam de questionar a maneira com que a arte é utilizada no que tange a disseminar pensamentos em relação a tais assuntos. Cotejando três objetos artísticos diferentes este texto pretende discorrer de que maneira a "violência" tem sido tratada desde a literatura, a música e o cinema a partir de uma leitura sobre a articulação conceitual do termo.

Palavras-chave: violência, literatura, música, cinema. 


\section{I - Qual violência?}

Os poemas do espanhol Antonio Machado, dos anos 1899/1907, organizam-se em torno do tema "soledades". São poemas no estilo de um romantismo decadente e remetem à contemplação do espaço frente à passagem do tempo natural e às recordações subjetivas. Faz parte desse conjunto, o texto "Recuerdo infantil":

Una tarde parda y fría

de invierno. Los colegiales

estudian. Monotonía

de lluvia tras los cristales.

Es la clase. En un cartel

se presenta a Caín

fugitivo, y muerto Abel

junto a una mancha carmín.

Con timbre sonoro y hueco

truena el maestro, un anciano

mal vestido, enjuto e seco,

que lleva a un libro en la mano.

Y todo un coro infantil

va cantando la lección:

mil veces ciento, cien mil,

mil veces mil, un millón.

Una tarde parda y fría

de invierno. Los colegiales

estudian. Monotonía

de la lluvia en los cristales(1).

Minuciosamente, ouvem-se as batidas dos pingos da chuva nas janelas da sala de aula onde estão os colegiais a estudar sob a monotonia do tempo "frio e pardo", frente a um professor descrito como "um ancião mal vestido, enxuto e seco" que, com um livro nas mãos, ensina lições de matemática que são respondidas em forma de coro "mil vezes cem, cem mil, / mil vezes mil, um milhão". A descrição dos colegiais que estudam tranqüilamente seria harmônica e límpida não fosse pelo detalhe a que o poeta faz referência: uma estrofe que mostra uma passagem bíblica, o assassinato de Abel - caído junto a uma mancha vermelha - cometido por Caim, fugitivo.

Na história do cristianismo, a partir dos escritos bíblicos, a morte de Abel por seu irmão é considerada a primeira atitude de violência de um homem para com outro e o primeiro homicídio na história da humanidade desde a criação do mundo por Deus. Pelo assassinato cometido, Caim é privado das benevolências divinas e lançado à terra como um errante condenado à imortalidade. 
$\mathrm{Na}$ cultura cristã, a história de Caim e Abel é transmitida às crianças quando elas já possuem maturidade para compreender algumas regras de bom relacionamento. A partir do exemplo, é postulado que atentar contra o outro utilizando a força física é atentar contra as leis de Deus, anteriores às do homem e definidas pelos Dez Mandamentos(2). Desde esse primeiro quadro, fica clara a relação direta que o conceito de violência mantém com o cristianismo, fato que se registra também em relação à maioria das religiões que existem no mundo.

Apesar da monotonia no colégio, sob o ruído da chuva que implica calmaria e tranqüilidade, a projeção do assassinato de Abel mostra que as crianças possivelmente já conhecem a violência enquanto um tipo de atentado contra as leis divinas. Nem por isso, a calmaria na sala de aula significa que ali se pratica a lição aprendida, uma vez que a Bíblia apenas explica que Caim matou Abel por ciúmes. Não seria a alegoria do quadro, dentro do poema, uma crítica ao fato de se transmitir aos colegiais uma história como aquela, sem as devidas relativizações? Pois, ainda que seja "pecado", cometer um ato de violência parece ser algo próprio da natureza humana. Às vezes o que se tem para discutir não é por quais motivos se mata, mas porque o ser humano apesar de ser "racional" leva consigo, durante toda a vida, pulsões incontroláveis diante de formas de raciocinar que ele mesmo desenvolve.

Em "Conversa sobre violência", entrevista dada a Jacqueline Sers da revista francesa Reforme, 1978, Rolland Barthes explica, a partir de uma dimensão religiosa, a palavra violência. Para ele - como a história bíblica de Caim e Abel as religiões das grandes civilizações sempre equiparam a violência ao mal, mas também ao direito, em crenças mais arcaicas. De acordo com Barthes, os problemas que constituem as discussões que giram em torno da violência estariam ligados às convenções e por isto dever-se-ia primeiramente definir sobre que tipo de violência se discute, estando aí entendida a violência institucionaliza - da lei, da política ou do Estado - e a violência que parte de ações individuais.

A violência de Caim contra Abel parte de sua natureza individual, enquanto poder-se-ia supor que a atitude de Deus para com Caim tivesse sido uma violência da lei, ou deste estado primeiro em que Deus se coloca. No decorrer da entrevista, Barthes mostra como tratar a violência, já que o impasse entre individual/coletivo seria de responsabilidade da cultura filosófica herdada pelo ocidente:

Há duzentos anos, fomos acostumados pela cultura filosófica e política a valorizar enormemente, digamos, o coletivismo em geral. Todas as filosofias são filosofias da coletividade, da sociedade, e o individualismo é muito malvisto. Já não há ou é muito rara a 
filosofia do não-gregarismo, da pessoa. Talvez justamente seja preciso assumir essa singularidade, não vivê-la como uma espécie de desvalorização, de vergonha, mas repensar efetivamente uma filosofia do sujeito. Não se deixar intimidar por esta moral, difundida em nossa sociedade, que é a moral do superego coletivo, com seus valores de responsabilidade e de engajamento político. Talvez seja preciso aceitar o escândalo de posições individualistas, embora tudo isso precisasse ser mais definido. (3)

Repensar esses duzentos anos de história filosófica seria criticar a história recente quando crimes em massa foram/são cometidos pela humanidade contra si própria. Como exemplos poderiam ser citados os episódios da escravidão dos negros africanos no processo de colonização dos impérios europeus até meados do século XX, além do holocausto cometido durante a Segunda Guerra Mundial contra os judeus.

Seguindo o raciocínio de Barthes, a história filosófica deveria ter se preocupado com as questões do indivíduo frente ao coletivo, para talvez tornar possível ingressar em um entendimento das razões que regem a natureza do homem. Mas se Rousseau, em seu Contrato social, já entendia a sociedade como algo que distorce a personalidade natural do ser humano, já não estaria aí uma resposta a Barthes?

Um exemplo atual de violência está na canção "Violência" do Titãs, grupo brasileiro de rock, que nasceu no seio do regime militar e, no final dos anos 70 e início dos 80, revelava o momento que a juventude brasileira vivia. A canção "Violência" composta por Sergio Brito e Charles Gavin faz parte do álbum Jesus não tem dentes no país dos banguelas, de 1987, e não só traz consigo várias idéias que discutem a relação coletivo/indivíduo diante da questão da violência nas grandes cidades, como retoma a questão a que Barthes se refere, enquanto direito de uma civilização, a partir da colagem de um fragmento da "Dissertação do papa sobre o crime seguido de orgia", do Marquês de Sade:

O movimento começou, o lixo fede nas calçadas.

Todo mundo circulando, as avenidas congestionadas.

o dia terminou a violência continua.

Todo mundo provocando todo mundo nas ruas.

A violência está em todo lugar.

Não é por causa do álcool,

nem é por causa das drogas.

A violência é nossa vizinha,

Nem é só por culpa sua,

Nem é só por culpa minha.

Violência gera violência.

Violência doméstica, violência cotidiana,

são gemidos de dor, todo mundo se engana...

Você não tem o que fazer, saia pra rua,

Pra quebrar minha cabeça ou pra que quebrem a sua. 
Violência gera violência.

Com os amigos que tenho não preciso de inimigos.

Aí fora ninguém fala comigo.

Será que tudo está podre, será que todos estão vazios?

Não existe razão, nem existem motivos.

Não adianta suplicar porque ninguém responde.

Não adianta implorar todo mundo se esconde.

É difícil acreditar que somos nós os culpados,

É mais fácil culpar deus ou então o diabo.

"O crime é venerado e posto em uso por toda a terra,

de um pólo a outro se imolam vidas humanas.

No reino de zópito os pais degolam os próprios filhos,

seja qual for o sexo, desde que não lhes agrade.

Os coreanos incham o corpo da vítima a custa de vinagre

e depois de estar assim inchado, matam-no a pauladas.

Os irmãos Morávios madavam matar com cócegas". (4)

O movimento nas ruas contextualiza uma coletividade, um número extenso de pessoas que vive nos grandes centros já acostumados com uma violência "cotidiana", a qual continua mesmo quando elas não estão nas avenidas "congestionadas": a violência está "em todo lugar", não é consequiência de algo como droga ou álcool. O "eu lírico" da canção descreve este estado de violência (5) em que não existem motivos ou culpados, no entanto, seu discurso é por si mesmo questionado na medida em que se propõe a fazer perguntas sobre a causa da situação, assumindo por fim sua culpa e a das outras pessoas, ainda que seja mais fácil não resolver o problema culpando simplesmente a "deus ou o diabo".

Mesmo assim, a canção termina com o fragmento da "Dissertação do papa sobre o crime seguido de orgia", do Marquês de Sade, um discurso que universaliza a violência a partir de projeções de cultos considerados "crimes" na civilização ocidental. No entanto, esses seriam também atos do cotidiano, quase distantes do mal como vimos a partir do primeiro quadro. Pela universalização do crime, a violência é parte daquilo que compõe a sociedade sem que os atores que a executam sejam considerados criminosos, o que questiona o próprio conceito de violência.

O refrão mostra a violência como resultado de si própria "violência gera violência" - o que mostra a necessidade de evitá-la. Enfim, o que a canção de fato traz relaciona-se à falta de sentido nas relações do homem com o homem, no niilismo que não abre mais as portas para a gentileza ou o amadurecimento de si: "será que tudo está podre, será que todos estão vazios?" Apesar do verso seguinte dizer que "não existe razão nem existem motivos", não seria o próprio vazio e a perda da esperança os motivos para que a violência seja cometida? 


\title{
II - 0 espetáculo
}

Espetacularizar a violência tornou-se lugar comum na sociedade do século XX, acostumada com os conflitos entre Estados produtores da guerra, com os problemas que constituem as guerrilhas e a violência urbana, que impedem de se distinguir mocinho de vilão. Os crimes como assassinatos, sequestros, estupros e assaltos ocorrem em série, como se a própria civilização tivesse se tornado uma indústria da barbárie.

Essas reflexões foram exploradas por Walter Benjamin (6), em textos como "O narrador: considerações sobre a obra de Nikolai Leskov" e "A obra de arte na era de sua reprodutibilidade técnica". Ao escrever sobre uma estética de guerra, ele mostrou como a humanidade pode se tornar umvoyeur de seu próprio sofrimento e destruição, tal como se assistisse a um espetáculo semelhante aos que eram oferecidos aos deuses olímpicos na época de Homero. Supõe-se, mais que isso, que a humanidade produz e oferece via arte um meio de as pessoas assistirem à barbárie da qual é produtora. Para Benjamin, nesse processo, o cinema teria lugar privilegiado:

\begin{abstract}
o cinema é a forma de arte correspondente aos perigos existentes mais intensos com os quais se confronta o homem contemporâneo. Ele corresponde a metamorfoses profundas do aparelho perceptivo, como as que experimenta o passante, numa escala individual, quando enfrenta o tráfico, e como as experimenta, numa escala histórica, todo aquele que combate a ordem social vigente. (7)
\end{abstract}

A partir dessa definição do papel do cinema, a humanidade como voyeur de sua própria catástrofe, qual tem sido sua resposta a essas imagens? O próprio Benjamin sabe que em primeiro lugar o cinema é uma arte de entretenimento: "a recepção através da distração, que se observa crescentemente em todos os domínios da arte e constitui o sistema de transformação profunda nas estruturas perceptivas, tem no cinema o seu cenário privilegiado" (8)

Com relação a alguns filmes que abordam o tema da violência contemporaneamente, a experiência tem sido interessante no sentido de propor diálogos diretos com a realidade. Mas a indústria cultural cinematográfica também lança enxurradas de filmes que, assim como as da chuva, vêm e vão a cada estação provocando seus estragos e são esquecidas até que chova forte outra vez. Não querendo aqui apresentar o divisor de águas em que, de um lado, teríamos o chamado cinema de autor ou cinema de arte e, de outro lado, o cinema de entretenimento de longas filas nos shoppings centers, poderíamos dizer que o espectador que busca um tipo específico de diversão e elege um tema como a violência, naturalmente tem como objetivo consumir um produto que lhe mostre exatamente o que ele quer ver, sem 
necessariamente fazê-lo pensar sobre o que acontece no mundo, muito menos mudá-lo.

Em 2008, esteve nas telas de alguns cinemas do Brasil umremake do filme Funny Games (9), cujo título em português foi Violência gratuita. Do alemão Michael Heneke, Violência gratuita foge da linguagem usual utilizada em filmes que abordam a violência como tema central, uma que vez que, ao impor um pacto com o espectador, rompe com a catarse, forçando a platéia a questionar sua participação na trama em que está diretamente envolvida.

Tal como na canção dos titãs, o filme de Heneke questiona, por exemplo, o que motivaria a violência cometida por dois jovens simpáticos e aparentemente abastados que invadem a casa de uma família em férias e lhe infringem, de maneira muito sutil e sem procedimentos ou linguagens rudimentares, um jogo psicológico e cruel cuja violência física é simplesmente uma opção que, contudo, não podem evitar. Georg, o pai, pergunta a Peter e Paul, os jovens agressores, o que os motivou a agir contra sua família.

Georg: Por que estão fazendo isto?

Paul (a Peter): Balofo, porque está fazendo isto? (Peter mexe os ombros respondendo não saber). Vamos diga-nos!

Peter: Não sei.

Paul: O capitão quer saber. "Porquê?" E aí?

Peter: É difícil falar sobre isso. Eu...

Peter (a Paul): Não se acanhe.

Peter (a Paul): Sabe como é difícil.

Paul: Meu Deus que confusão! O pai dele (explica a Georg) se divorciou quando ele era magro e arrumou outra.

Peter: Isso não é verdade! Ele está mentindo! Foi minha mãe quem se divorciou por que... (Peter chora).

Paul (a Georg e Anna): Porque ela queria ficar com o ursinho dela só para ela. Desde então, ele tem sido bicha e um escroto. Estão vendo?

(Dirige-se a Peter): Você é um cretino! A verdade é que ele é de uma família suja depravada. Tem cinco irmãos e irmãs todos viciados. o pai é alcoólatra e a mãe, já pode imaginar, a verdade é que ele é quem trepa com ela. (Peter chora). Embora duro, é a verdade.

(A Peter): Vamos, acalme-se.

Georg (a Paul): Você é nojento! Pare com estas obscenidades na frente de uma criança.

Paul (a Georg): Desculpe. Claro. De que resposta gostaria? O que o satisfaria? Mas o que eu disse não é verdade, sabe muito bem disso. Olhe para ele. Acha mesmo que é de família necessitada? (Peter e Paul riem). Certo. Ele é um bostinha mimado atormentado pelos problemas ecológicos do mundo agravados por uma existência vazia! Isto é duro, francamente. Está vendo (diz Paul a Georg para que olhe para Peter) sorriu de novo. Muito bem, está satisfeito? Ou quer outra versão?

Peter: Estou com fome. Vou ver o que tem. (Levanta-se e vai à cozinha). (Paul se aproxima de Georg e faz um comentário quase como um cochicho): A verdade é que ele é um viciado em drogas. Por isso ele está assim. Por isto é meio pancado. Eu também sou um viciado. Nós dois roubamos famílias ricas para sustentar nosso vício.

Georg (a Peter): Quer parar com esta loucura! Já entendi o recado. Isso não lhe basta? (10) 
Os mesmos motivos que não gerariam a violência em "Violência" dos Titãs são aqui postos em dúvida pelo diretor, a partir das tentativas de resposta que Paul articula a fim de justificar sua atitude e a atitude de Peter. São traumas familiares, distúrbios psicológicos, drogas. Nada disso, contudo, justifica a ação dos dois. Os rapazes não portavam quaisquer tipos de armas quando se aproximaram da casa de Georg. E o "jogo" só começa a partir de uma agressão que Paul sofre de Georg. Mesmo que a trama nos responda que se trata mesmo de um jogo divertido que os rapazes gostam de fazer com as famílias - ao todo são três famílias vítimas dos rapazes no filme eles não poderiam ser identificados como meros bandidos. Enquanto personagens, eles são utilizados para testar a reação do espectador, que é seu parceiro no jogo.

A estratégia utilizada por Heneke, atribuindo plenos poderes a esses dois personagens, faz com que, mesmo cúmplice, o espectador não conheça quais são as regras do jogo, de modo que, em algumas falas, o diretor antecipa o que poderia acontecer, caso a trama seguisse certas regras conhecidas no cinema onde o mal não prevalece. Na sala de TV, depois da morte do filho, o casal encontra-se mais uma vez refém dos jogos de Peter e Paul. Estão ambos machucados e cansados.

Dentre os jogos propostos por Paul, o "esposa amorosa" ou "Na faca ou a tiro: perder sua vida pode ser divertido" daria poderes a Anna caso ela vencesse, para escolher qual o tipo de morte seria conveniente para seu esposo, se com facadas, ou com um tiro. Georg ouvindo intercede pedindo a esposa para que não os responda e pede aos dois rapazes para que acabem logo com o "jogo". Entretanto, o que consta para o diretor não reside em terminar com o "jogo" segundo a vontade da vítima ou a do espectador, pois, implicaria em um final convencionalmente feliz próprio de algumas ficções cujo tema é sobre violência e onde o "bem" vence no final. A resposta de Paul é a seguinte:

Paul (a Georg): Ah, isso é covardia! O filme ainda não chegou ao fim. (Dirige-se ao espectador, olhando diretamente para a câmera): Isso já chega? Mas você quer um final real, com um desfecho plausível, não é? (Volta a se dirigir a Georg): A aposta ainda vale e não pode ser retirada unilateralmente.

o jogo segue, com Paul desafiando Anna a escolher a forma de execução do marido e a recitar uma oração, mas a dona de casa responde que não sabe rezar. Dessa forma, é Peter quem lhe dita a oração: "Senhor pai, me torne bonzinho pra no céu eu ter meu ninho". Além de ensinar Anna a rezar, Paul a orienta a fazê-lo com "as mãos juntas apontadas em direção ao céu." Ora, não haveria nessa cena uma subversão da ideia que foi analisada no primeiro quadro do trabalho? Se, para a maioria das religiões, a violência está associada ao mal, como se 
explica o fato de em Funny games, o algoz ensinar sua vítima a rezar? Essa é também uma cena em que o diretor trabalha com uma espécie de metalinguagem, antecipando, pelo discurso de Paul, o que ocorre em seguida.

Atenta aos movimentos e vendo que um fuzil se encontra sobre a mesa, Anna atira em Peter e o mata. Imediatamente, Paul transforma a situação assumindo o controle do filme, como se não houvesse um diretor, e demonstrando que há uma relação particular entre os jogadores: a violência é uma força dominante, não há chances para a sobrevivência da vítima que, bem ou mal, também está jogando. Após Anna recitar a oração, Paul diz a ela: "Essa foi de ensaio. Agora, vamos para a medalha de ouro. Se conseguir recitar a oração, que é curta demais... de trás para frente, sem errar, não só pode escolher quem dos dois bate a bota primeiro mas também, e isso vai lhe interessar mais, como." Com um controle remoto, ele reedita a cena e intercede em seu desfecho, antes que Anna atire.

- que Paul fala não serve como regra para Anna, mas para ele. - que pedia era que Anna recitasse a oração de trás pra frente como condição para que pudesse fazer a escolha, contudo, ela quebra as regras do jogo. E assim é que Paul, de forma regressiva, de "trás pra frente", volta a cena em que Peter seria morto. O grande vencedor do jogo, que escolhe por fim quem será a próxima vítima e de que forma morrerá, é Paul. Por trás dele está Heneke, o diretor. E o espectador nada pode diante disso. Eles atiram em Georg e o filme segue.

O assassinato de Anna, ao final do filme, compreende a inevitável vitória dos rapazes que discutem felizes sobre as fronteiras entre o real e a ficção, a partir de teorias físicas, enquanto passeiam no barco da família com Anna ainda viva e amarrada.

Peter: Mas onde eu estava?

Paul: No problema da comunicação entre matéria e anti-matéria.

Peter: Exato. Como se estivesse num buraco negro a força da gravidade é tão forte que nada lhe escapa. Silêncio total.

Paul: Que horas são?

Peter: Como?

Paul: Que horas são?

Peter: Oito e pouco.

Paul: Já? (Paul empurra Anna para dentro da água). Adeus Bela!

Peter (diante da atitude de Paul): Por quê? O horário era as nove. Ela

ainda tinha quase uma hora.

Paul: Primeiro, estava difícil navegar assim e segundo, estou começando a ter fome.

Peter: Isso é verdade. (Ambos riem). Quando Kelvin supera a força da gravidade acontece que um universo é real, mas o outro é ficção.

Paul: Como pode?

Peter: Sei lá. Era uma espécie de modelo de projeção no ciberespaço.

Paul: E onde está seu herói agora? Na realidade ou na ficção?

Peter não responde.

Paul: Mas a ficção é real não é?

Peter: Como assim? 
Paul: Bem, a gente vê nos filmes.

Peter: Claro.

Paul: Ela é tão real quanto a realidade que agente vê certo?

Peter: Besteira.

Paul: Por quê?

Os personagens seguem questionando o espectador, que admite e consome a violência presente em muitos filmes de ficção que lhe proporcionam bem-estar, a partir da projeção de supostos heróis. Pela simples catarse, o espectador não se importa se a violência que viu na tela é a mesma que ocorre na esquina, nas ruas. No entanto, na medida em que Heneke rompe com essa catarse, ele leva o leitor para dentro da "realidade" de seu filme, levando-o a refletir sobre a relação dos homens entre si.

Por esses três quadros, percebemos que a arte serve para questionar as relações do homem com a sociedade: apontando seus excessos, chamando a atenção para as várias formas de violência e contra-violência, problematizando as relações entre cultura e barbárie.

\section{Resumen}

Las relaciones entre comunicación y representaciones icnográficas en los días actuales sobrepasan lo esperado con la descubierta de la fotografía y del cine. Existen artistas que utilizan el arte para explorar asuntos que están de moda, otros tratan de cuestionar la manera como el arte es utilizado. Través de tres objetos artísticos diferentes, este texto pretende analizar de qué manera la violencia es tratada en la literatura, música y cine partiendo de una lectura acerca de la articulación conceptual del termo.

Palabras-clave: violencia, literatura, música, cine.

\section{Notas}

[1] MACHADO, 1944. p.24.

[2] Encontra-se em "Êxodo", capítulo 20, versículos 1 a 17, e em "Deuteronômio", capítulo 5, versículos 1 a 21. A BÍLIA SAGRADA. Antigo e o Novo Testamento. São Paulo: Sociedade Bíblica do Brasil, 2004.

[3] BARTHES, 2005. p. 213-214.

[4] Titãs. Jesus não tem dentes no país dos banguelas. São Paulo: Warner Music, 1987 .

[5] O álbum anterior, "Cabeça Dinossauro" de 1985, traz também uma canção de composição de Charles Gavin "Estado violência" na qual, preferencialmente, o cidadão é subordinado ao Estado a que pertence: "Sinto no meu corpo / a dor que angustia. / A lei ao meu redor, / a lei que eu não queria. / Estado violência, / estado hipocrisia. / A lei que não é minha, / a lei que eu não queria. / Meu corpo não é meu, / meu coração é teu. / Atrás de portas frias / o homem está só. / Homem em silêncio / homem na prisão / homem no escuro / o futuro da nação. / Estado violência, / deixem- 
me querer. / Estado violência, / deixem-me pensar. / Estado violência, / deixem-se sentir. / Estado violência, deixem-me em paz. Cf. Titãs. Cabeça dinossauro. São Paulo: Warner Music, 1986. Faixa 05, 3:11 min.

[6] BENJAMIN, 1994.

[7] BARTHES, 2005. p.213-214.

[8] 1994. p.194.

[9] NIGRE, André. Eu vi um Brasil no cinema. Bravo! Ano 11. n. 132. Brasil: Editora Abril, ago./2008.

[10] Áustria/França, 1997.

[11] As transcrições são da tradução de Harbour Master, do filme Violências gratuitas.

\section{Referências bibliográficas}

BARTHES, Rolland. Inéditos: política. V.4. São Paulo: Martins Fontes, 2005. BENJAMIN, Walter. Magia e técnica, arte e política: ensaios sobre literatura e história da cultura. v. I. Tradução de Sérgio Paulo Rouanet. 7. ed. São Paulo: Brasiliense, 1994.

MACHADO. Antônio. Obra poética. Pleamar: Bueno Aires, 1944.

VIOLÊNCIA GRATUITA. Direção de Michel Heneke, 1997. VHS. 103min., son., color. 